\title{
The effect of a new drag-law parameterization on ice shelf water plume dynamics
}

Article

Published Version

Wilchinsky, A. V., Feltham, D.L. and Holland, P. R. (2007) The effect of a new drag-law parameterization on ice shelf water plume dynamics. Journal of Physical Oceanography, 37 (7). pp. 1778-1792. ISSN 0022-3670 doi:

https://doi.org/10.1175/JPO3093.1 Available at https://centaur.reading.ac.uk/35314/

It is advisable to refer to the publisher's version if you intend to cite from the work. See Guidance on citing.

Published version at: http://dx.doi.org/10.1175/JPO3093.1

To link to this article DOI: http://dx.doi.org/10.1175/JPO3093.1

Publisher: American Meteorological Society

All outputs in CentAUR are protected by Intellectual Property Rights law, including copyright law. Copyright and IPR is retained by the creators or other copyright holders. Terms and conditions for use of this material are defined in the End User Agreement.

www.reading.ac.uk/centaur 
Central Archive at the University of Reading

Reading's research outputs online 


\title{
The Effect of a New Drag-Law Parameterization on Ice Shelf Water Plume Dynamics
}

\author{
AleXANDER V. WilchinSKY* \\ Centre for Polar Observation and Modelling, Department of Earth Sciences, University College London, London, United Kingdom
}

Daniel L. Feltham

Centre for Polar Observation and Modelling, Department of Earth Sciences, University College London, London, and British Antarctic Survey, Cambridge, United Kingdom

PAUl R. Holland

British Antarctic Survey, Cambridge, United Kingdom

(Manuscript received 7 August 2006, in final form 5 October 2006)

\begin{abstract}
A drag law accounting for Ekman rotation adjacent to a flat, horizontal boundary is proposed for use in a plume model that is written in terms of the depth-mean velocity. The drag law contains a variable turning angle between the mean velocity and the drag imposed by the turbulent boundary layer. The effect of the variable turning angle in the drag law is studied for a plume of ice shelf water (ISW) ascending and turning beneath an Antarctic ice shelf with draft decreasing away from the grounding line. As the ISW plume ascends the sloping ice shelf-ocean boundary, it can melt the ice shelf, which alters the buoyancy forcing driving the plume motion. Under these conditions, the typical turning angle is of order $-10^{\circ}$ over most of the plume area for a range of drag coefficients (the minus sign arises for the Southern Hemisphere). The rotation of the drag with respect to the mean velocity is found to be significant if the drag coefficient exceeds 0.003; in this case the plume body propagates farther along and across the base of the ice shelf than a plume with the standard quadratic drag law with no turning angle.
\end{abstract}

\section{Introduction}

Floating ice shelves form the interface between grounded ice sheets and the ocean. Melting and freezing at the base of Antarctic ice shelves modifies several Antarctic water masses (Rivaro et al. 2003; Foldvik et al. 2004) that are precursors to Antarctic Bottom Water, the most prevalent water mass in the world. In regions of sea ice formation adjacent to ice shelves, such as polynyas, salty water at the surface freezing temperature is formed that is dense enough to sink and flow down the continental shelf slope toward the ice

* Additional affiliation: Institute of Mathematics and Mechanics, Kazan State University, Kazan, Russia.

Corresponding author address: Alexander V. Wilchinsky, CPOM, UCL, Gower Street, London WC1E 6BT, United Kingdom.

E-mail: aw@cpom.ucl.ac.uk shelf grounding line; this water is known as high-salinity shelf water (HSSW; see Fig. 1). As seawater's freezing temperature decreases with increasing pressure and therefore depth, the HSSW is warm enough to melt the ice shelf base near the grounding line. The meltwater released cools and freshens the ambient seawater to form buoyant ice shelf water (ISW). ISW subsequently flows along the base of the ice shelf, melting and freezing at the shelf base and thus redistributing ice mass. ISW plumes are believed to be particularly important in redistributing mass under the Filchner-Ronne Ice Shelf (Antarctica), the most voluminous ice shelf on earth. The path of ISW plumes is affected by topography, buoyancy forces, Coriolis force, and basal drag, as was demonstrated by Holland and Feltham (2006) who used an ISW model with plume dynamics based on the earlier work of Jungclaus and Backhaus (1994).

The typical approach to modeling plume drag at the shelf-ocean boundary is to treat the magnitude of the drag as proportional to the square of the depth-

DOI: $10.1175 / J P O 3093.1$

(C) 2007 American Meteorological Society 


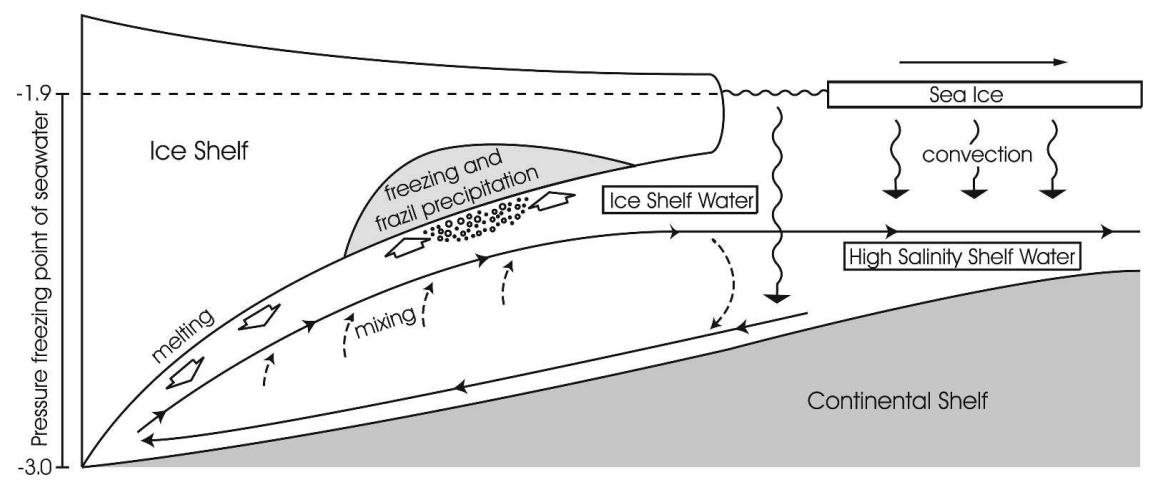

FIG. 1. Schematic diagram showing processes involved in ice shelf-ocean interaction.

averaged plume speed, with the drag aligned with the mean plume velocity. Since the angle between the classical solution for Ekman drag and the geostrophic velocity is $\pm 45^{\circ}$, one would clearly expect the role of rotation to be important when the thickness of the plume is only moderately larger than the Ekman layer thickness, and its mean velocity deviates significantly from the geostrophic velocity.

Brown (1974) considered drag in an atmospheric boundary layer by equating the velocity and vertical velocity gradient in the Ekman layer and turbulent boundary layer solutions at some undetermined reference height above the boundary. In this case, the drag depends upon the reference height, which was supposed to be determined experimentally. We also consider solutions within the Ekman and turbulent boundary layers: however, our approach differs from Brown's in that we formally asymptotically match the Ekman and turbulent boundary layer solutions. This approach is both more mathematically rigorous and, importantly, removes the need for the introduction of an ad hoc reference height, which would be extremely difficult to measure beneath an ice shelf.

We determine a new drag law that takes account of the change in direction and magnitude of the drag relative to the depth-mean velocity in a plume. Although we focus on the impact of this new drag law on the dynamics of an ISW plume, the new drag law clearly has much wider applicability to solid-fluid boundaries, such as the land/ice-air boundary, the sea ice-ocean boundary, and bottom boundary currents in the ocean.

In the next section, we consider the effect of Ekman rotation in the drag law. The result of our analysis is a new drag law relating the drag magnitude and direction to the mean plume velocity and depth. In section 3 , we briefly describe the parts of an existing ISW plume model that are affected by the drag law and present calculations of plume paths and thickness that demonstrate the significant effect that our drag law has on the plume dynamics. In section 4, we summarize and present our concluding remarks.

\section{Drag law accounting for Ekman rotation}

We consider the idealized case of a fluid (ocean) flow parallel to a flat, horizontal bottom in a rotating reference frame. The aim is to relate the mean velocity of a fluid layer (plume) of an arbitrary thickness $H$ above the bottom to the fluid traction (drag) at the bottom. We consider the flow to be steady and horizontally homogeneous.

Far away from the bottom the flow is geostrophic with the constant geostrophic velocity $\mathbf{U}$ determined by the balance between the Coriolis force and horizontal pressure gradient force: $f \mathbf{k} \times \mathbf{U}=-(1 / \rho) \nabla p$, where $\mathbf{k}$ is the vertical unit vector pointing up and away from the bottom, $\boldsymbol{\nabla}=[\partial / \partial x, \partial / \partial y]$, where $x$ and $y$ are the horizontal coordinates, $p$ is pressure, $\rho$ is the fluid (ocean) density, and $f$ is the Coriolis parameter, positive in the Northern Hemisphere and negative in the Southern Hemisphere. The pressure gradient does not depend on the vertical coordinate $z$, and we set the bottom to be at $z=0$ with $z$ increasing with distance above the bottom. For convenience, we align the $x$ axis with the geostrophic velocity so that $\mathbf{U}=[U, 0]$.

We denote the departure of the velocity $\mathbf{u}$ from the geostrophic velocity $\mathbf{U}$ by tildes, so that $\tilde{\mathbf{u}}=[u-U, v]$. The departure velocity is significant only in the Ekman layer and is known as the Ekman velocity. The Ekman layer has thickness $\delta_{E}=\left(2 A_{m} /|f|\right)^{1 / 2}$, where $A_{m}$ is the maximum value of the vertical eddy viscosity $A_{v}$. Scaling the vertical coordinate with the Ekman layer depth $\xi=z / \delta_{E}$, the Ekman velocity satisfies

$$
[\tilde{u},-\tilde{v}]=\frac{s_{f}}{2} \frac{d}{d \xi}\left(a_{v} \frac{d \tilde{\mathbf{u}}}{d \xi}\right),
$$

where $a_{v}=A_{v} / A_{m}$ and $s_{f}=\operatorname{sgn}(f)$ returns the sign of $f$. Since the turbulent boundary layer is much shallower 
than the Ekman layer, $a_{v} \sim 1$, and (1) yields the standard Ekman layer solution (e.g., Pedlosky 1979)

$$
\begin{aligned}
{[\tilde{u}, \tilde{v}]=} & U e^{-\xi}\left[\left(u_{0} \cos \xi+s_{f} v_{0} \sin \xi\right),\right. \\
& \left.-\left(v_{0} \cos \xi+s_{f} u_{0} \sin \xi\right)\right],
\end{aligned}
$$

where $u_{0}=\tilde{u}(0) / U$ and $v_{0}=\tilde{v}(0) / U$ are the normalized bottom Ekman velocity components.

The Ekman solution (2) is not valid close to the bottom because the eddy diffusivity $a_{v}$ rapidly drops to zero as the bottom is approached. The reduction in $a_{v}$ as the bottom is approached gives rise to the turbulent boundary layer. Although the turbulent boundary layer is much thinner than the Ekman layer, its presence significantly alters the standard Ekman solution. The standard Ekman solution with a no-slip bottom boundary condition gives rise to $\mathrm{a} \pm 45^{\circ}$ turning angle between the geostrophic velocity and the bottom shear, which is not observed. The presence of the turbulent boundary layer is normally accounted for by imposing a drag law as the bottom boundary condition in the Ekman solution. In mathematical terms, such a procedure is rigorous only if it allows matching of the turbulent layer solution with the Ekman solution. The possibility of such matching was questioned by Brown (1974), who found that these solutions do not match if one used a constant eddy diffusivity in the Ekman layer and an eddy diffusivity that varies linearly with distance from the bottom in the turbulent boundary layer. In appendix A we show that rigorous matching is possible when the turbulent eddy diffusivity determining the Ekman layer and turbulent boundary layer is a smooth function of distance from the bottom. Moreover, such a matching naturally leads to imposing a drag condition at the bottom of the of Ekman solution:

$$
\left.\rho A_{m} \frac{d \tilde{\mathbf{u}}}{d z}\right|_{z=0}=\frac{\rho A_{m} U}{\delta_{E}}\left[s_{f} v_{0}-u_{0},-\left(s_{f} u_{0}+v_{0}\right)\right]=\tau,
$$

where $\tau$ is the constant shear stress in the turbulent boundary layer.

The appearance of the unknown bottom shear stress in the boundary condition for the Ekman layer flow requires us to consider a drag law. As the Coriolis force is not important in the turbulent boundary layer, there is no rotation of the velocity with regard to the bottom stress within the layer, and we assume that the velocity in the layer intermediate to it and the Ekman layer is aligned with the bottom shear stress (cf. Taylor 1915; Brown 1974). The flow external to the turbulent boundary layer is $\mathbf{u}=[U+\tilde{u}, \tilde{v}]$, which we use at the bottom in a drag law with the form

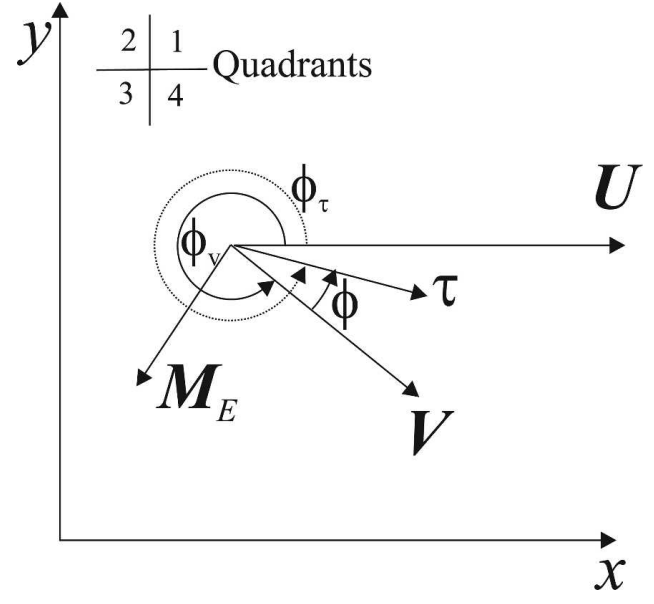

FIG. 2. The angles between the geostrophic velocity, mean velocity, and the shear traction.

$$
\boldsymbol{\tau}=\rho r(b) \mathbf{u}(0),
$$

where $b=\left[u(0)^{2}+v(0)^{2}\right]^{1 / 2}$ is the bottom speed. The standard quadratic drag law assumes $r=C_{q} b$, where $C_{q}$ is the drag coefficient.

Consider a plume flowing over the bottom with thickness $H$. Since the Ekman velocity decays rapidly with distance from the bottom, it is reasonable to assume that the Ekman mass flux lies entirely within the thickness of the plume, which includes both the Ekman layer and geostrophic flow. The total Ekman mass flux [given by integration of the departure velocity (2) between $z=0$ and $z=\infty$ ] is

$$
\mathbf{M}_{E}=\frac{U \delta_{E}}{2}\left[u_{0}+s_{f} v_{0}, v_{0}-s_{f} u_{0}\right]
$$

We denote the mean velocity over the plume as $\mathbf{V}$, which is

$\mathbf{V}=[1,0] U+\frac{1}{H} \mathbf{M}_{E}=\frac{U \delta_{E}}{2 H}\left[2 H / \delta_{E}+u_{0}+s_{f} v_{0}, v_{0}-s_{f} u_{0}\right]$.

The counterclockwise rotation angle from the geostrophic velocity directed along the $x$ axis to the mean velocity $\mathbf{V}$ (Fig. 2) is given by (6) to be

$$
\phi_{V}=\arctan \left(\frac{v_{0}-s_{f} u_{0}}{2 H / \delta_{E}+u_{0}+s_{f} v_{0}}\right),
$$

while the counterclockwise rotation angle from the geostrophic velocity to the bottom shear traction $\tau$ is given by (3) to be

$$
\phi_{\tau}=\arctan \left(\frac{-v_{0}-s_{f} u_{0}}{s_{f} v_{0}-u_{0}}\right) .
$$


The counterclockwise angle between the shear traction and the mean velocity, hereinafter referred to as the turning angle, is therefore given by

$$
\phi=\phi_{\tau}-\phi_{V}
$$

The shear traction magnitude is given by (3) to be

$$
\tau=\frac{\rho A_{m} U}{\delta_{E}}\left[2\left(u_{0}^{2}+v_{0}^{2}\right)\right]^{1 / 2},
$$

where the geostrophic speed $U$ is related to the mean plume speed $V \equiv\|\mathbf{V}\|$ by

$$
U=\frac{2 H V}{\delta_{E}}\left[\left(2 H / \delta_{E}+u_{0}+s_{f} v_{0}\right)^{2}+\left(v_{0}-s_{f} u_{0}\right)^{2}\right]^{-1 / 2}
$$

[from (6)].

Combining the turning angle (9) and shear traction magnitude (10) allows us to write the drag law (4) in the form

$$
\boldsymbol{\tau}=r_{E} \mathbf{Q}(\phi) \cdot \mathbf{V}
$$

where

$$
r_{E}=\frac{2 \rho A_{m} H}{\delta_{E}^{2}}\left[\frac{2\left(u_{0}^{2}+v_{0}^{2}\right)}{\left(2 H / \delta_{E}+u_{0}+s_{f} v_{0}\right)^{2}+\left(v_{0}-s_{f} u_{0}\right)^{2}}\right]^{1 / 2},
$$

and the matrix $\mathbf{Q}(\phi)$ rotates the drag direction counterclockwise from the direction of $\mathbf{V}$ by the turning angle $\phi$. In appendix B, we present the special cases of our drag law when the turbulent boundary drag (4) adopts a linear form and show that for an Antarctic ISW plume the typical turning angle is $-10^{\circ}$.

\section{The role of Ekman rotation in an ISW plume model}

\section{a. The mathematical model of an ISW plume}

The ISW plume model is described fully by Holland and Feltham (2006), and the reader is referred to that paper for further details. The plume model consists of a parameterization of ice shelf basal melting and freezing and a frazil ice model, which are coupled to an unsteady, reduced-gravity plume model developed by Jungclaus and Backhaus (1994). In the model, active regions of ISW evolve above and within an expanse of stagnant ambient fluid with a fixed, statically stable vertical stratification. The horizontal extent of the plume is determined by a wetting and drying scheme, whereby the boundary of the active plume area, in which the governing equations are solved, evolves according to simple rules (Jungclaus and Backhaus 1994).
Here we focus on the role of the drag experienced by the plume as it flows over the ice shelf base in determining the plume path and depth. Since we consider the case in which the plume does not freeze, frazil ice does not form and, hence, plays no role in the plume dynamics. Integrating over the plume depth, we obtain a volume conservation equation for the plume that determines its depth:

$$
\frac{\partial H}{\partial t}+\boldsymbol{\nabla} \cdot(H \mathbf{V})=e^{\prime}+m^{\prime}
$$

where $\mathbf{V}=\left[V_{x}, V_{y}\right]$ is the depth-averaged plume velocity, $e^{\prime}$ is the rate at which ambient water is entrained into the moving plume, and $m^{\prime}$ is the melting (or freezing) rate at the ice shelf base (defined to be positive for melting).

The plume momentum balance in an arbitrary horizontal Cartesian coordinate system $(x, y)$ is given by

$$
\begin{aligned}
\frac{\partial\left(H V_{x}\right)}{\partial t}+\boldsymbol{\nabla} \cdot\left(H \mathbf{V} V_{x}\right)= & \boldsymbol{\nabla} \cdot\left(A_{h} H \boldsymbol{\nabla} V_{x}\right)+\frac{g H^{2}}{2 \rho_{0}} \frac{\partial \rho}{\partial x} \\
& -g^{\prime} H \frac{\partial B}{\partial x}-\tau_{x}+f H V_{y} \text { and }
\end{aligned}
$$

$$
\begin{aligned}
\frac{\partial\left(H V_{y}\right)}{\partial t}+\boldsymbol{\nabla} \cdot\left(H \mathbf{V} V_{y}\right)= & \boldsymbol{\nabla} \cdot\left(A_{h} H \boldsymbol{\nabla} V_{y}\right)+\frac{g H^{2}}{2 \rho_{0}} \frac{\partial \rho}{\partial y} \\
& -g^{\prime} H \frac{\partial B}{\partial y}-\tau_{y}-f H V_{x},
\end{aligned}
$$

where $g$ is gravitational acceleration, $A_{h}=100 \mathrm{~m}^{2} \mathrm{~s}^{-1}$ is the horizontal eddy viscosity, and $B$ is the plume ambient water depth. The seawater density $\rho$ is determined using a linear equation of state $\rho=\rho_{0}[1+$ $\beta_{s}\left(S-S_{0}\right)-\beta_{T}\left(T-T_{0}\right)$ ], where $T$ is temperature, $S$ is salinity, $\rho_{0}=1030 \mathrm{~kg} \mathrm{~m}^{-3}, T_{0}=-2.0^{\circ} \mathrm{C}, S_{0}=34.5 \mathrm{psu}$, $\beta_{s}=7.86 \times 10^{-4} \mathrm{psu}^{-1}$, and $\beta_{T}=3.87 \times 10^{-5}{ }^{\circ} \mathrm{C}^{-1}$. The reduced gravity is $g^{\prime}=\left(\rho-\rho_{a}\right) g / \rho_{0}$, where $\rho_{a}$ is the ambient seawater density. Our new drag law (12) enters the momentum balance through the drag components $\left[\tau_{x}, \tau_{y}\right]$.

The scalar transport equations describing the vertically integrated balances of heat and salt are

$$
\begin{aligned}
\frac{\partial(H T)}{\partial t}+\boldsymbol{\nabla} \cdot(H \mathbf{V} T)= & \boldsymbol{\nabla} \cdot\left(K_{h} H \boldsymbol{\nabla} T\right)+e^{\prime} T_{a}+m^{\prime} T_{b} \\
& -\gamma_{T} V\left(T-T_{b}\right)
\end{aligned}
$$

and

$$
\frac{\partial(H S)}{\partial t}+\boldsymbol{\nabla} \cdot(H \mathbf{V S})=\boldsymbol{\nabla} \cdot\left(K_{h} H \boldsymbol{\nabla} S\right)+e^{\prime} S_{a}
$$


(the salinity of the ice shelf ice is negligible). Here $T_{a}$ and $S_{a}$ are the temperature and salinity of the ambient fluid at the plume-ambient interface, $T_{b}$ is the temperature at the interface between the ice shelf and ocean, and $\gamma_{T}$ is a coefficient representing the transfer of heat in the adjacent boundary layer. We assume that the eddy diffusivity of heat and salt $K_{h}$ is equal to the eddy viscosity for momentum $A_{h}$.

The new drag law does not enter the entrainment rate $e^{\prime}$, to which we refer the reader to Holland and Feltham (2006), but does enter the melt rate and heat transport equation through the transport coefficients for heat $\left(\gamma_{T}\right)$ and salt $\left(\gamma_{S}\right)$, which are functions of the friction velocity at the ice shelf base. The basal melt rate $m^{\prime}$ is determined from the balances of heat and salt at the ice shelf plume boundary:

$$
c_{0} \gamma_{T} V\left(T-T_{b}\right)=m^{\prime} \mathcal{L}+m^{\prime} c_{I}\left(T_{b}-T_{I}\right)
$$

and

$$
\gamma_{S} V\left(S-S_{b}\right)=m^{\prime} S_{b},
$$

where $\mathcal{L}=3.35 \times 10^{5} \mathrm{~J} \mathrm{~kg}^{-1}$ is the latent heat of ice fusion, $c_{0}=3974 \mathrm{~J} \mathrm{~kg}^{-1}{ }^{\circ} \mathrm{C}^{-1}$ is the specific heat capacity of seawater, $c_{I}=2009 \mathrm{~J} \mathrm{~kg}^{-1}{ }^{\circ} \mathrm{C}^{-1}$ is the specific heat capacity of ice, $T_{I}=-25^{\circ} \mathrm{C}$ is the core temperature of the ice shelf, a value appropriate to the Filchner-Ronne Ice Shelf, $S_{b}$ is the plume ambient interface salinity, and $\gamma_{S}$ is the salt transfer coefficient in the boundary layer. The third term in (19) is an approximation of heat conduction within the ice shelf; we assume that salt does not leach through the ice. The interface quantities $T_{b}$ and $S_{b}$ are constrained by a linearized pressure freezing temperature relation:

$$
T_{b}=a S_{b}+b-c B,
$$

where $a=-0.0573^{\circ} \mathrm{C} \mathrm{psu}^{-1}, b=0.0832^{\circ} \mathrm{C}$, and $c=$ $-7.61 \times 10^{-4}{ }^{\circ} \mathrm{C} \mathrm{m}^{-1}$. Equations (19)-(21) are combined to solve for $m^{\prime}$ and, thus, $T_{b}$. The dimensionless transfer coefficients are given by

$$
\gamma_{T}=\frac{u_{*} / V}{2.12 \ln \left(u_{*} H / \nu\right)+12.5 \operatorname{Pr}^{2 / 3}-9}
$$

and

$$
\gamma_{S}=\frac{u_{*} / V}{2.12 \ln \left(u_{*} H / \nu\right)+12.5 \mathrm{Sc}^{2 / 3}-9},
$$

respectively, where the friction velocity $u_{*}=(\tau / \rho)^{1 / 2}$ contains the new drag magnitude given by (10). The other parameters are the molecular viscosity $\nu=1.95 \times$ $10^{-6} \mathrm{~m}^{2} \mathrm{~s}^{-1}$, the molecular Prandtl number $\operatorname{Pr}=13.8$, and the molecular Schmidt number of seawater Sc $=$ 2432.

In the Holland and Feltham (2006) ISW plume model, and all preceding plume models, the drag at the ice shelf base, hereafter referred to as the "conventional drag law," is given by

$$
\boldsymbol{\tau}=C_{q}\|\mathbf{V}\| \mathbf{V} .
$$

The new drag law, hereinafter referred to as the "proposed drag law," is given by (12), and we take a quadratic dependence of drag on speed so that $\left[u_{0}, v_{0}\right]$ are determined by the quadratic equations

$$
u_{0}-s_{f} v_{0}=-\gamma\left(1+u_{0}\right) \text { and } u_{0}+s_{f} v_{0}=-\gamma s_{f} v_{0} \text {, }
$$

where

$$
\gamma=\frac{\delta_{E} C_{q} U}{A_{m}}\left[\left(1+u_{0}\right)^{2}+v_{0}^{2}\right]^{1 / 2},
$$

with the mean plume speed $V$ determining the geostrophic speed $U$ using (11). The proposed drag law differs from the conventional drag law both in that the drag is rotated with respect to the mean velocity by the angle $\phi$ given by (9) and the drag magnitude is different, determined by $r_{E}$ in (12).

\section{b. Model setup}

Since we are interested in exploring the role of the new drag law, we restrict ourselves to an idealized ice shelf base topography with depth $D$ given by the analytical solution for an unconfined ice shelf with constant mass flux (Morland 1987; MacAyeal and Barcilon 1988):

$$
D=\frac{\gamma_{1}}{\left(\gamma_{2}+y\right)^{1 / 2}},
$$

where the axes $x$ and $y$ are directed eastward (along slope) and northward (upslope), respectively, and the constants $\gamma_{1}$ and $\gamma_{2}$ are determined by the grounding line thickness and the mass flux. There is no variation in ice shelf draft in the $x$ direction. The constants $\gamma_{1}$ and $\gamma_{2}$ were chosen to provide a draft distribution representative of Filchner-Ronne Ice Shelf, decreasing from around $1400 \mathrm{~m}$ at the grounding line to $400 \mathrm{~m}$ at the ice front (Sandhäger et al. 2004) over a span of $600 \mathrm{~km}$ (Fig. 3). This gives the shelf base angle of slope to be about $0.75^{\circ}$ at the grounding line.

We present model calculations using both conventional and proposed drag laws to determine the role of the modified drag law in determining the dynamics of the ISW plume. Both drag laws depend upon the value of the drag coefficient $C_{q}$. A commonly adopted value for the drag coefficient is 0.0025 (MacAyeal 1984; Makinson 2002), while Döös et al. (2004) found 0.008 in the Baltic Sea, and Holland and Jenkins (1999) and Holland and Feltham (2006) used 0.0015 for an ice shelf 


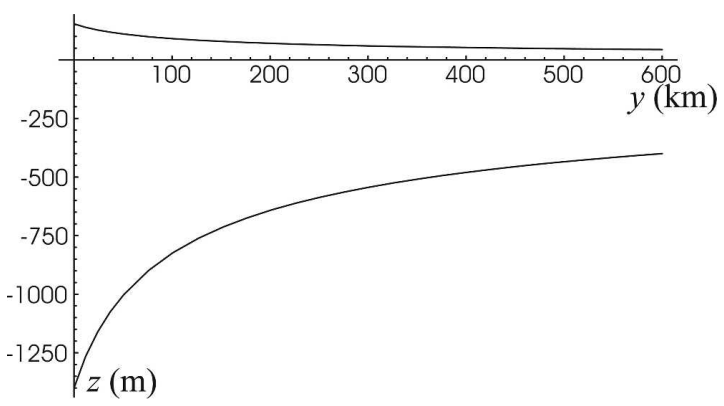

FIG. 3. The adopted ice shelf profile extending northward. There is no shelf variation in ice shelf draft in the $x$ direction.

base. The latter value was justified by the presumed smoothness of the ice shelf base, but recent observations of significant roughness of the Fimbul Ice Shelf base (Nicholls et al. 2006), obtained using an autonomous submarine, suggest that larger values of the drag coefficient may be appropriate.

The proposed drag law depends upon the maximum vertical eddy viscosity $A_{m}$, which also appears in the Ekman layer thickness $\delta_{E}$. To estimate $A_{m}$, we consider a vertical eddy viscosity approximation suitable for turbulence caused by bottom friction in neutrally or stably stratified flows (Ezer and Weatherly 1990):

$$
A_{v}=k u_{*} z\left[1-\frac{\left(z-Z_{\max }\right)^{2}}{\left(H_{m}-Z_{\max }\right)^{2}}\right] e^{-z / Z_{\max }},
$$

where $H_{m}$ is the mixed layer thickness and for neutral stratification $Z_{\max } \approx 0.16 u_{*} /|f|$. The eddy viscosity reaches its maximum at $z=Z_{\max }$ determining $A_{m}=$ $0.16 k u_{*}{ }^{2} /(|f| e) \approx 0.0235 C_{q} b^{2} /|f|$, where we have used $u_{*} \approx C_{q}^{1 / 2} b$. For the bottom speed estimated through the mean plume speed (see appendix B) $b=0.03 \mathrm{~m} \mathrm{~s}^{-1}$, $C_{q}=3 \times 10^{-3}$, and $|f| \approx 10^{-4} \mathrm{~s}^{-1}$, we estimate the maximum vertical eddy viscosity in our analysis $A_{m}$ to be approximately $5 \times 10^{-4} \mathrm{~m}^{2} \mathrm{~s}^{-1}$.

\section{c. Numerical simulations}

The plume momentum, mass, and scalar transport equations were solved using standard finite differences on a Cartesian grid. We used a spatial step of $\Delta x=$ $\Delta y=1 \mathrm{~km}$, a time step of $450 \mathrm{~s}$, and latitude $78^{\circ} \mathrm{S}$. All results were found to display grid independence. To initiate an ISW plume, we assume that the intrusion of dense HSSW to the grounding line causes melting of the ice shelf base. The ISW plume inflow next to the grounding line $(y=0)$ is arbitrarily set to be an area 10 $\mathrm{km}$ wide containing a fixed plume depth of $5 \mathrm{~m}$. Since the computational domain is solely determined by the plume extent and the shelf base depth is independent of $x$, the $x$ coordinates of the inflow are arbitrary. We investigated the effect of varying the initial plume thickness by a factor of 4 and found it to have no significant impact on our results. The properties of the plume at the inflow are given by an equal mixture of ambient water and meltwater according to Gade (1979) and described in Holland and Feltham (2006). The ambient fluid has properties appropriate for the ocean cavity under the Filchner-Ronne Ice Shelf: a salinity profile which decreases linearly from 34.71 psu at the grounding line depth to $34.5 \mathrm{psu}$ at the surface, and a temperature rising linearly from $-2.18^{\circ} \mathrm{C}$ at the grounding line to $-1.9^{\circ} \mathrm{C}$ at the surface (Jenkins and Bombosch 1995). The relatively fresh ISW is less dense than the ambient fluid and flows up the underside of the ice shelf. Unless otherwise stated, the model calculations were terminated after 100 days, which was sufficient time for the differences between simulations with and without the new drag law to become apparent.

The modeled ISW plume thicknesses for the conventional drag law and the proposed drag law are presented in Fig. 4 for $C_{q}=0.001,0.003$, and 0.005. The horizontal lines are isobaths of the ice shelf draft with a $100-m$ contour interval. The ISW plume initially flows upslope but is diverted leftward by the Coriolis force, with subsequent upslope transport caused by Ekman draining. For $C_{q}=0.001$ the plume thickness and front position given by the different drag models are very similar. As the drag coefficient increases to 0.005 , the along-slope front of the conventional model retreats by about $100 \mathrm{~km}(20 \%)$, while that of the proposed model advances by about $10 \mathrm{~km} \mathrm{(2 \% ).} \mathrm{At} \mathrm{the} \mathrm{same} \mathrm{time} \mathrm{the}$ upslope front of the conventional model advances slightly, by around $8 \mathrm{~km}(6 \%)$, while that of the proposed model advances more significantly, by around 25 $\mathrm{km}(20 \%)$.

To investigate the different plume behavior with the proposed drag law, we calculated the areally averaged values of the plume velocity and thickness, turning angle, and the significant terms appearing in the $x$ component of the momentum balance for simulations using the conventional drag law, the proposed drag law with artificially imposed zero turning angle, and the full proposed drag law (Tables 1-3). As the ice shelf profile does not vary in the $x$ direction, the pressure terms in the $x$ direction cancel each other in calculating the mean, and the nonlinear advective terms are negligible. For the same drag coefficient $C_{q}$, the drag magnitude $\tau_{x}$ is usually larger for the conventional model because the proposed drag law uses the velocity in the lower Ekman layer, which is lower than the mean velocity.

In Fig. 5, we compare the results of the conventional and proposed drag models with $C_{q}=0.005$ (Figs. 5a,b) with results produced by the conventional drag model with artificially imposed varying turning angle given by 

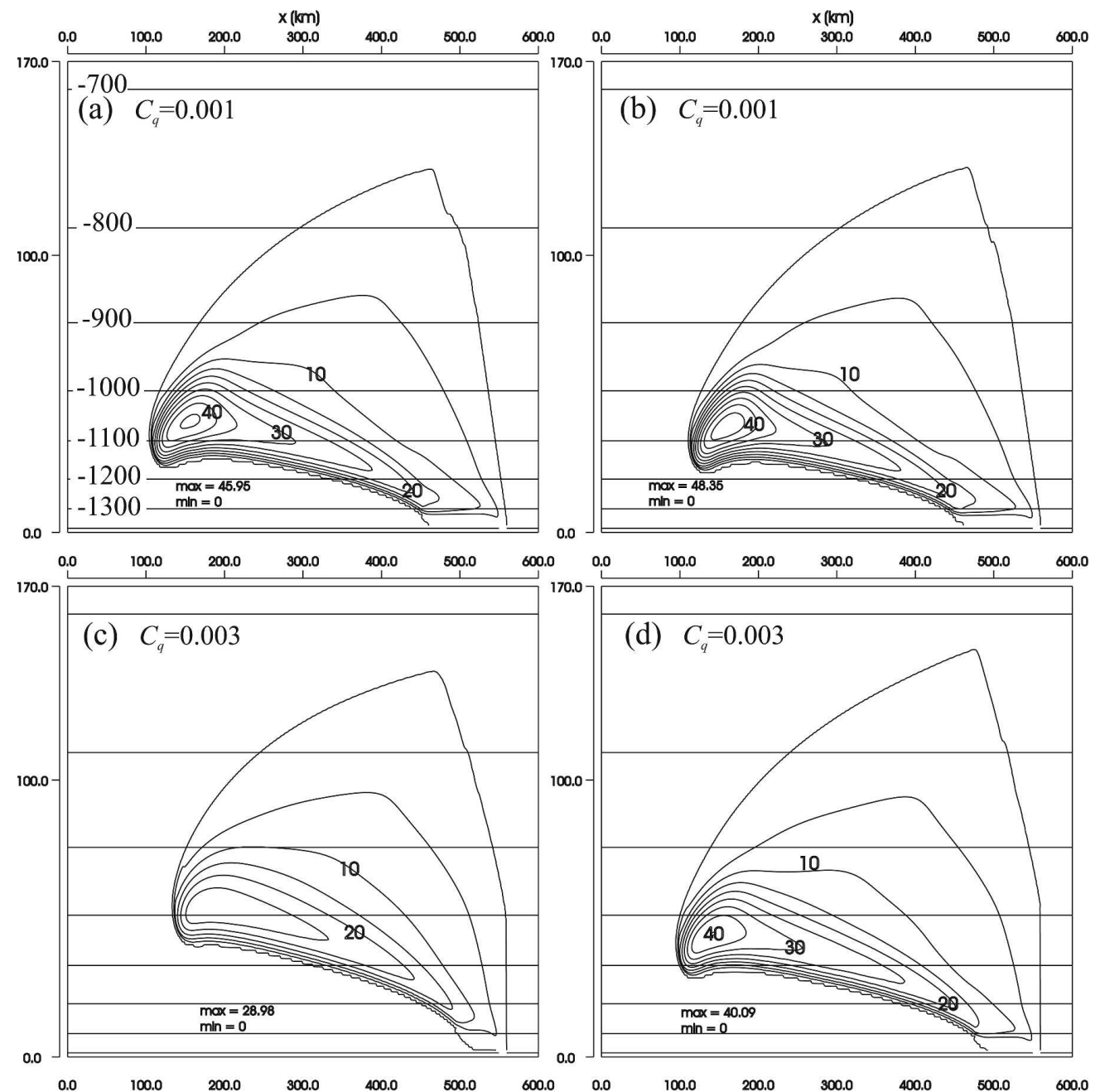

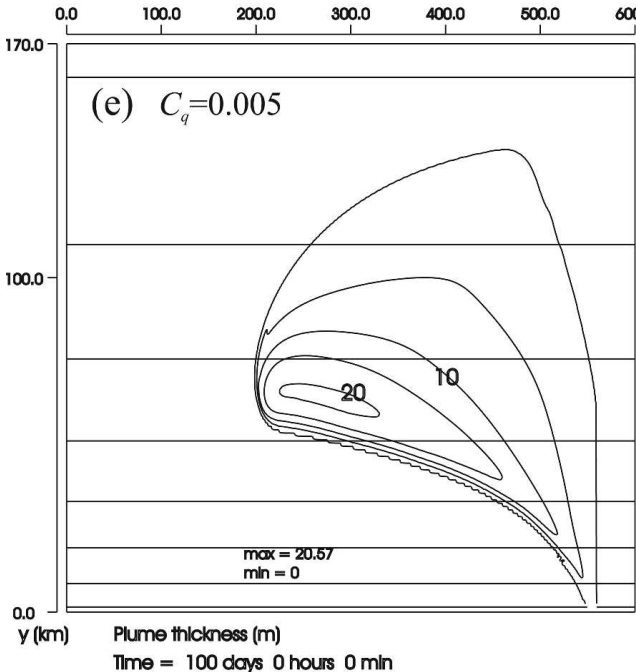

Conventional drag model

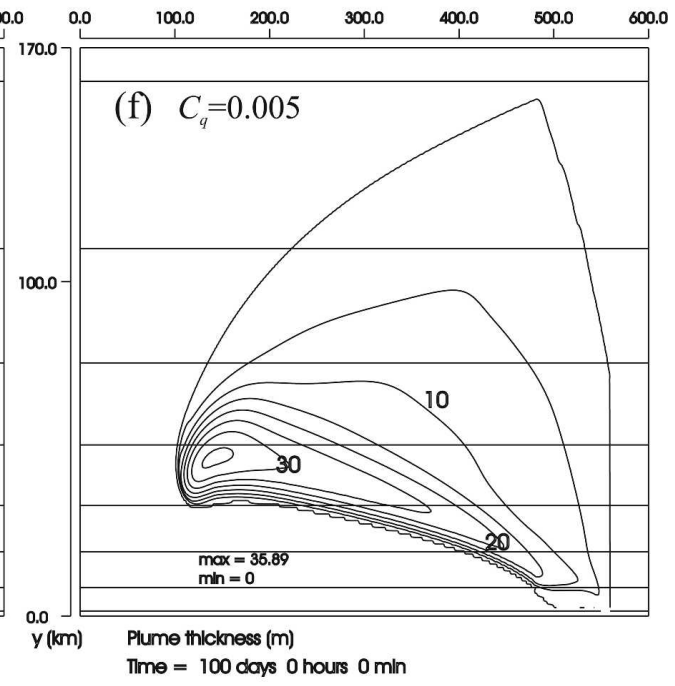

Proposed drag model

FIG. 4. The ISW plume thickness contours for (left) the conventional drag model and (right) the proposed drag model for three drag coefficient values: 0.001, 0.003, and 0.005. The horizontal lines are the ice shelf isobaths and are shown every $100 \mathrm{~m}$; contour lines in the plume are shown every $5 \mathrm{~m}$. 
TABLE 1. Conventional drag model.

\begin{tabular}{ccccccccc}
\hline \hline$C_{q}\left(10^{-3}\right)$ & $d\left(H V_{x}\right) / d t\left(10^{-6} \mathrm{~m}^{2} \mathrm{~s}^{-2}\right)$ & $\boldsymbol{\nabla} \cdot\left(A_{h} H \nabla V_{x}\right)$ & $-\tau_{x}$ & $f H V_{y}$ & $\phi\left({ }^{\circ}\right)$ & $V_{x}\left(\mathrm{~cm} \mathrm{~s}^{-1}\right)$ & $V_{y}$ & $H(\mathrm{~m})$ \\
\hline 1 & -0.15 & 1.41 & 1.65 & -3.18 & 0 & -3.64 & 0.266 \\
3 & -0.076 & 1.04 & 4.0 & -5.09 & 0 & -3.26 & 0.496 \\
5 & -0.039 & 0.75 & 4.58 & -5.36 & 0 & -2.7 & 0.634 \\
\hline
\end{tabular}

angle (9) (Fig. 5c) and the proposed drag model with zero turning angle, hereinafter called the "aligned proposed drag model" (Fig. 5d). It can be seen that the upslope advance of the proposed model is mainly determined by the negative mean turning angle that, if geostrophic balance is assumed, requires an additional velocity contribution directed eastward that rotates the velocity vector closer to the $y$ axis and allows the plume to propagate farther upslope.

Although the areally averaged turning angle in the proposed drag law is only of the order of several degrees, the typical turning angle values are much higher and correspond to the estimate of $-10^{\circ}$ found in appendix B, as plotted in Fig. 6 for the proposed drag model with $C_{q}=0.005$. The mean turning angle is lower because thin areas of the plume are characterized by a positive turning angle. In the Southern Hemisphere, the bottom drag lies in the fourth quadrant, as determined by (B3), while the Ekman mass flux vector given by (B2) lies in the third quadrant (Fig. 2). For thick plumes the Ekman mass flux contribution to the cumulative mass flux is small, the mean velocity direction is close to that of the geostrophic velocity, and the turning angle is negative. As the plume thickness decreases, however, the Ekman mass flux contribution increases, which leads to rotation of the mean velocity vector clockwise from the geostrophic velocity direction. At a particular plume thickness the mean velocity vector aligns with the bottom drag and, if the plume thickness decreases further, the turning angle becomes positive. The fraction of the plume volume with positive turning angle is, however, less than $5 \%$ of the whole plume volume.

If we choose the drag coefficient in the aligned proposed drag model to be 0.011 , then this provides the same spatially averaged drag along the $x$ axis as for the conventional drag model with $C_{q}=0.005$ at the end of the simulation at 100 days. Similarly, if the drag coef- ficient in the aligned proposed drag model is set to 0.03 , then this provides the same temporally and spatially averaged drag along the $x$ axis as for the conventional drag model with $C_{q}=0.005$ over the 100 days of simulation (being $\left\langle\tau_{x}\right\rangle=7.18 \times 10^{-6} \mathrm{~m}^{2} \mathrm{~s}^{-2}$ ). The plume thickness distributions determined by these drag coefficients used in the aligned proposed and proposed drag models are compared with the conventional drag model with $C_{q}=0.005$ in Fig. 7. For $C_{q}=0.011$, the plume thickness given by the proposed and aligned proposed drag models (Figs. 7c,d) deviates substantially from the conventional model with the same bottom drag at 100 days (Fig. 7a). It is clear that the equality of the drag magnitudes at the compared time does not result in a similarity of the along- $x$ plume fronts. Although adopting $C_{q}=0.03$ in the aligned proposed drag model (Fig. 7e) reduces the difference from the conventional model with $C_{q}=0.005$ (Fig. 7a) in the alongslope front position to $50 \mathrm{~km}(12.5 \%)$, the difference in the thickness distribution is still significant. The difference in the upslope front propagation between the proposed model with $C_{q}=0.03$ (Fig. 7f) and the conventional drag model with $C_{q}=0.005$ (Fig. 7a) is even more pronounced. The reason that such a behavior is possible is clear from Tables 1 and 2: the along-slope mass flux change rate is an order of magnitude smaller than the other terms in the momentum balance, so that a $10 \%$ difference in the balance of the other terms can lead to a much larger change in the mass flux change rate.

Interestingly, the differences described above between the propagation of the plumes using the conventional and proposed drag laws are significant only when melting is included in the ISW plume model. When no melting is present, the plume size is very small and its dynamics are identical to those of a dense, sinking gravity current. To investigate the role of melting, we simu-

TABLE 2. Proposed drag model with zero turning angle.

\begin{tabular}{ccccccccc}
\hline \hline$C_{q}\left(10^{-3}\right)$ & $d\left(H V_{x}\right) / d t\left(10^{-6} \mathrm{~m}^{2} \mathrm{~s}^{-2}\right)$ & $\boldsymbol{\nabla} \cdot\left(A_{h} H \nabla V_{x}\right)$ & $-\tau_{x}$ & $f H V_{y}$ & $\phi\left(^{\circ}\right)$ & $V_{x}\left(\mathrm{~cm} \mathrm{~s}^{-1}\right)$ & $V_{y}$ & $H(\mathrm{~m})$ \\
\hline 1 & -0.132 & 1.46 & 1.29 & -2.85 & 0 & -3.63 & 0.241 & 9.27 \\
3 & -0.111 & 1.3 & 2.74 & -4.13 & 0 & -3.57 & 0.38 & 9.15 \\
5 & -0.102 & 1.2 & 3.49 & -4.77 & 0 & -3.46 & 0.457 & 8.91 \\
11 & -0.074 & 1.05 & 4.53 & -5.64 & 0 & -3.25 & 0.575 & 8.46 \\
30 & -0.064 & 0.92 & 5.59 & -6.56 & 0 & -3 & 0.1 & 7.99 \\
\hline
\end{tabular}


TABLE 3. Proposed model.

\begin{tabular}{ccccccccc}
\hline \hline$C_{q}\left(10^{-3}\right)$ & $d\left(H V_{x}\right) / d t\left(10^{-6} \mathrm{~m}^{2} \mathrm{~s}^{-2}\right)$ & $\boldsymbol{\nabla} \cdot\left(A_{h} H \nabla V_{x}\right)$ & $-\tau_{x}$ & $f H V_{y}$ & $\phi\left(^{\circ}\right)$ & $V_{x}\left(\mathrm{~cm} \mathrm{~s}^{-1}\right)$ & $V_{y}$ & $H(\mathrm{~m})$ \\
\hline 1 & -0.105 & 1.43 & 1.26 & -2.76 & -1.5 & -3.59 & 0.238 \\
3 & -0.106 & 1.22 & 2.53 & -3.83 & -3.13 & -3.43 & 0.18 \\
5 & -0.081 & 1.07 & 3.07 & -4.21 & -3.84 & -3.25 & 0.441 & 8.7 \\
11 & -0.058 & 0.91 & 3.76 & -4.72 & -4.78 & -2.94 & 0.553 & 7.44 \\
30 & -0.045 & 0.75 & 4.32 & -5.11 & -5.54 & -2.58 & 0.672 & 6.61 \\
\hline
\end{tabular}

lated a gravity current flowing over a bed slope with the same geometry as the ice shelf base (effectively, we turned the ice shelf base upside down), used a homogeneous ambient, and imposed an influx density difference of $0.5 \mathrm{~kg} \mathrm{~m}^{-3}$ to drive the gravity current. We present results after a longer period of 200 days (instead of 100 days) in order to make the size of the gravity currents comparable to the ISW plumes considered above. As in the case of the ISW plumes, the conventional and proposed drag law models produced very similar results for a small drag coefficient of $C_{q}=$ 0.001. In Figs. 8a and 8b, we show the gravity current thickness for $C_{q}=0.005$ determined by the conventional and proposed drag laws. As can be seen in Figs. $8 \mathrm{a}$ and $8 \mathrm{~b}$, the difference in the along-slope front propagation between the different drag models is not significant. However, the gravity currents produced using the proposed and aligned proposed drag models are sig-

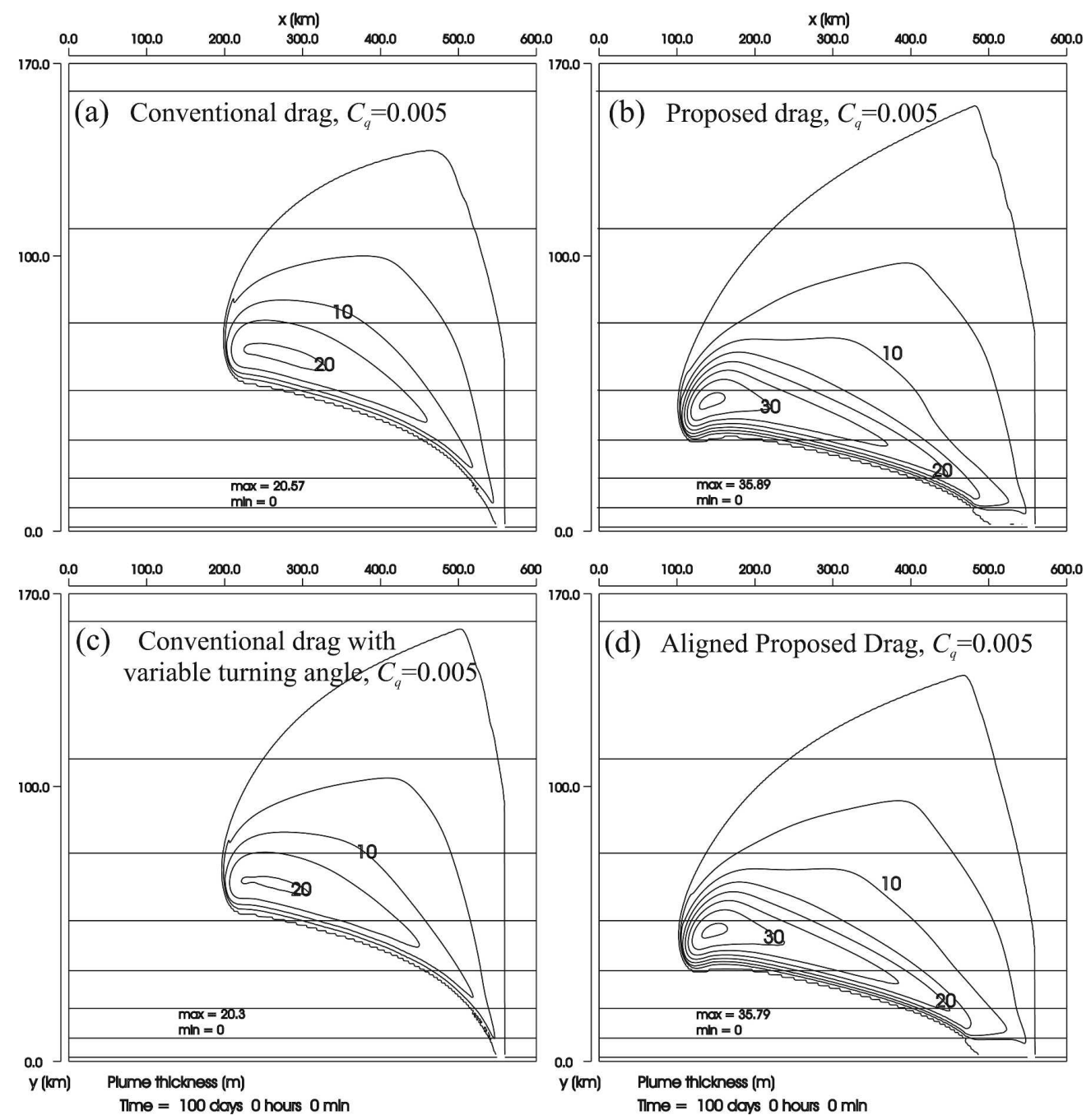

FIG. 5. The effect of the turning angle on the ISW plume thickness with a drag coefficient of 0.005 . 


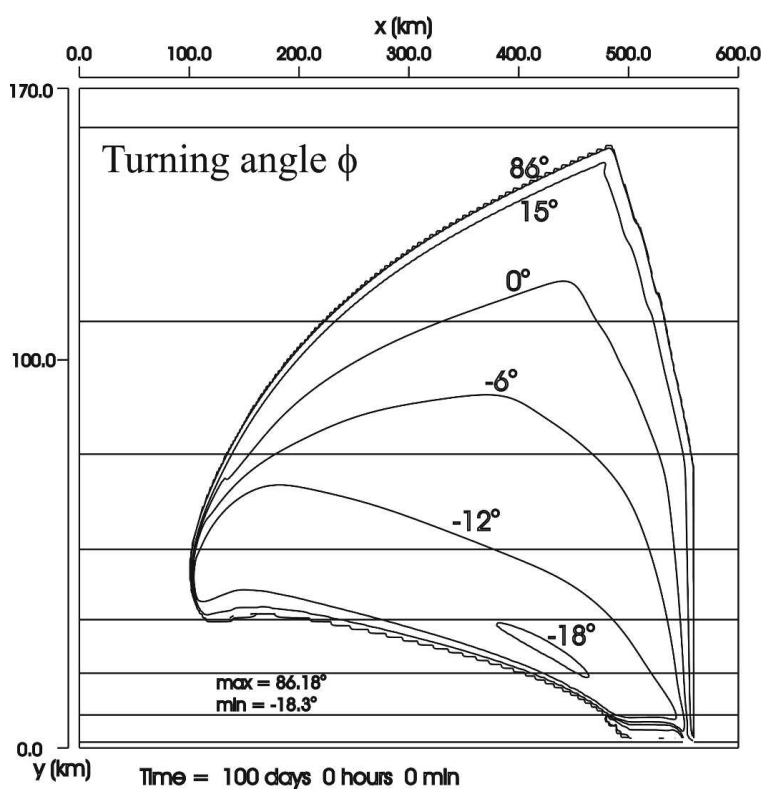

FIG. 6. The turning angle $\phi$ in the proposed drag model with a drag coefficient of 0.005 .

nificantly thicker than the current using the conventional drag model. Furthermore, the downslope (along y) propagation for the conventional model is slightly greater than the proposed model. The latter effect, however, is not due to the turning angle, but due to the higher bottom drag determined by the conventional model (for the same value of the drag coefficient). When the mean drag determined by the proposed model (when $C_{q}=0.02$ ) is similar to that of the conventional model with $C_{q}=0.005$ at 200 days, the mean gravity current thicknesses are also more similar, as well as their shape (Figs. 8c,d compared with Fig. 8a). Use of $C_{q}=0.036$ in the aligned proposed model equates its time-averaged shear stress (being $\left\langle\tau_{x}\right\rangle=$ $3.86 \times 10^{-6} \mathrm{~m}^{2} \mathrm{~s}^{-2}$ ) to that of the conventional model with $C_{q}=0.005$, and this drag coefficient produces a better correspondence in the thickness distribution between the aligned proposed model and the conventional model (Figs. 8e,f compared with Fig. 8a), although some difference remains. The corresponding momentum balance terms are given in Table 4, where "Yes" or "No" in the column headed "Ekm" denote the proposed and conventional drag model, respectively. If the Proposed drag model is used, but the rotation angle is zero in the table, then the turning angle was set to zero (i.e., the aligned proposed drag model was used).

To investigate the difference in the behavior of a buoyancy-driven flow with melting (the ISW plume) and a buoyancy-driven flow without melting (the gravity current), we show in Fig. 9 the along-slope and up- slope velocities $V_{x}$ (first row) and $V_{y}$ (second row) and the bottom drag $\tau_{x}$ (third row) for the ISW plume (left column) and the gravity current (right column). The proposed drag law with $C_{q}=0.005$ is used in all calculations. It can be seen that the gravity current is characterized by high velocity gradients only near its inflow and low velocity gradients elsewhere. In contrast, because melting adds buoyancy as the ISW plume propagates, the along-slope velocity of the plume decreases less rapidly as it flows up the slope. This difference in the velocity pattern produces the difference in the shear traction distribution $\tau_{x}$ along $x$. Such significant differences in the velocity and the drag distribution caused by the inclusion of melting determine the difference between the ISW plume and gravity current sensitivity to the drag law, as this is determined by the delicate balance between the momentum equation terms.

\section{Summary and concluding remarks}

We have considered the shear traction (drag) on a fluid as it flows past a solid boundary in the presence of rotation. We were able to show that the solution in the Ekman layer can be asymptotically matched to the solution in the turbulent layer adjacent to the boundary. This allowed us to write the drag at the boundary in terms of the velocity in the lower Ekman layer. We formulated a new drag law that relates the drag magnitude and (variable) direction to the depth-integrated mean velocity in a fluid layer and the depth of the layer. This drag law differs from more typical approaches in which the drag is collinear with the mean velocity, in both the drag magnitude and direction.

We investigated the effect of our new drag law in determining the dynamics of an ice shelf water plume beneath an idealized ice shelf using an ISW plume model developed previously (Holland and Feltham 2006). As the drag coefficient is increased, in line with recent observations of rough ice shelf basal topography (Nicholls et al. 2006), the differences in the ISW model predictions of plume path and depth using the new and old drag laws become more significant. The presence of the turning angle in the new drag law causes the plume to propagate farther upslope, while the changed drag magnitude leads to rather different along-slope dynamics. The latter effect was not present when we switched off melting at the ice shelf base, which acts to continually supply buoyancy to the plume. The role of drag in isolation from shelf melting was investigated through the simulation of (dense) gravity currents flowing over an upside-down shelf base. In these cases, the old and new drag laws can determine similar gravity current dynamics provided the drags are tuned so that they are of similar magnitude. 

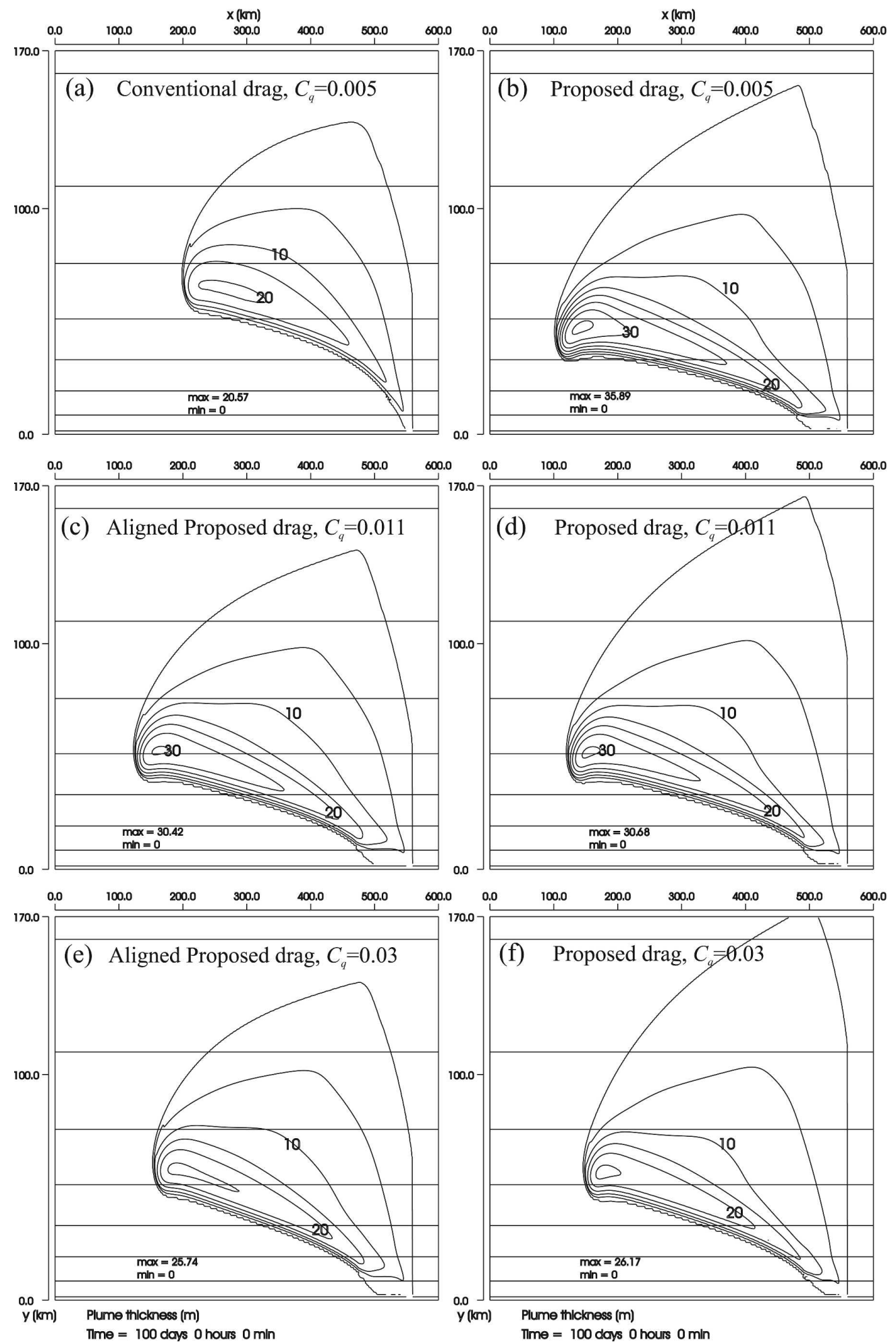

FIG. 7. (a)-(f) A comparison of the effect of the drag laws on the ISW model with similar $x$ component of basal drag $\left(\tau_{x}\right)$ values. Panels (c) and (d) show the proposed model results when the proposed model mean bottom drag $\tau_{x}$ is close to that of the conventional model 100 days after the plume initiation. Panels (e) and (f) show the proposed model results when the aligned proposed model mean bottom drag $\tau_{x}$, averaged in time, is close to that of the conventional model averaged in time. 

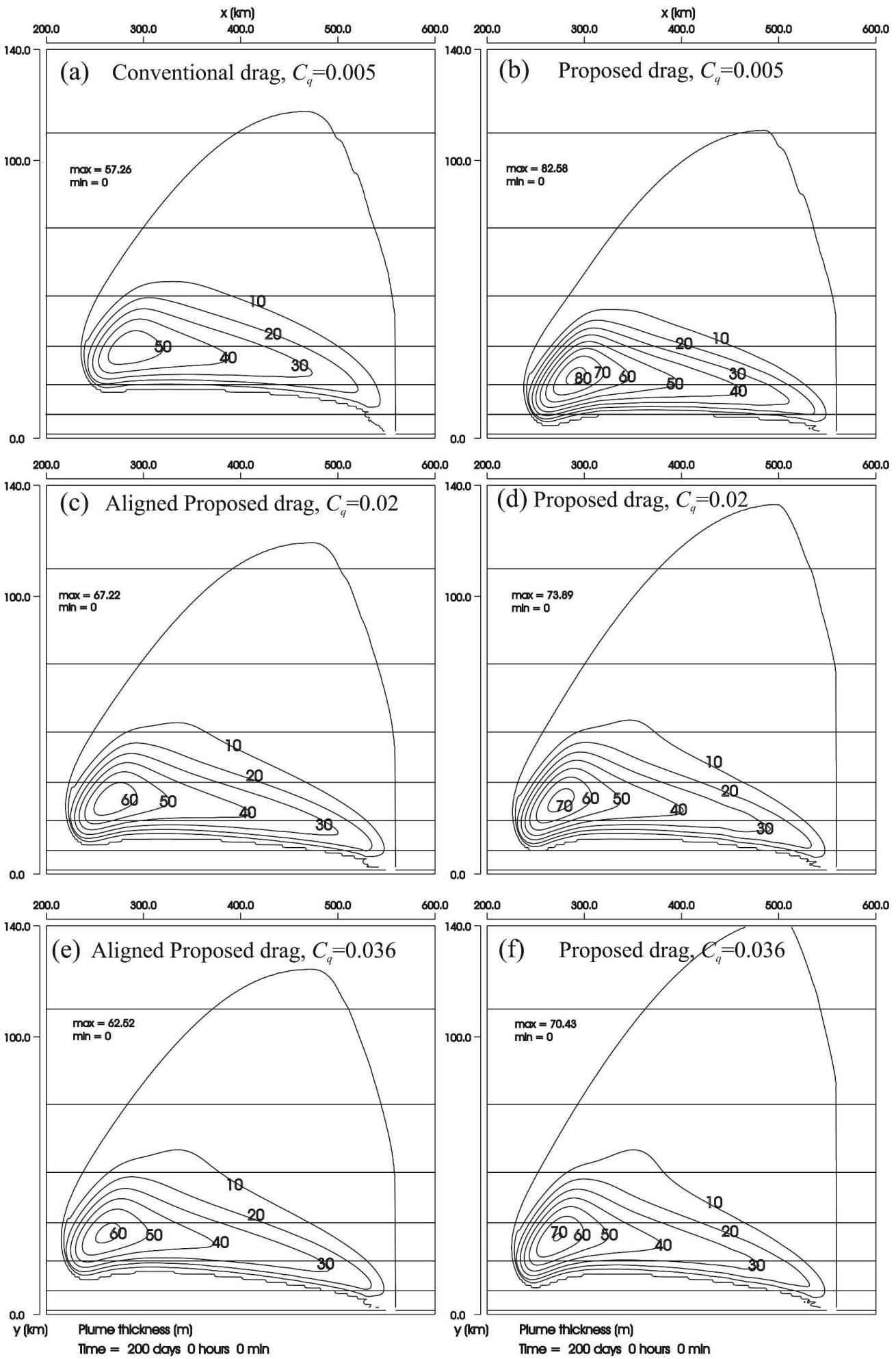

FIG. 8. The gravity current thickness contours for (a), (b) the conventional drag model and the proposed drag model for $C_{q}=0.05$, (c), (d) the aligned proposed drag model and proposed drag model for $C_{q}=0.02$, and (e), (f) the aligned proposed drag model and proposed drag model for $C_{q}=0.036$ at 200 days after its initiation. With the latter two values of drag coefficient, the values of the mean bottom drag along the $x$ axis at 200 days and the mean bottom drag averaged over 200 days of the aligned proposed model are similar to the drag values determined by the conventional model. The contour lines in the gravity current are shown every $10 \mathrm{~m}$. 
TABLE 4. Gravity current. See text for explanation of Ekm.

\begin{tabular}{clcccccccc}
\hline \hline$C_{q}\left(10^{-3}\right)$ & Ekm & $d\left(H V_{x}\right) / d t\left(10^{-6} \mathrm{~m}^{2} \mathrm{~s}^{-2}\right)$ & $\boldsymbol{\nabla} \cdot\left(A_{h} H \boldsymbol{\nabla} V_{x}\right)$ & $-\tau_{x}$ & $f H V_{y}$ & $\phi(\mathrm{deg})$ & $V_{x}\left(\mathrm{~cm} \mathrm{~s}^{-1}\right)$ & $V_{y}$ & $H(\mathrm{~m})$ \\
\hline 1 & No & -0.104 & 1.08 & 0.4 & -1.5 & 0 & -1.34 & 0.127 & 17.56 \\
1 & Yes & -0.107 & 1.15 & 0.29 & -1.45 & -0.335 & -1.33 & 0.116 & 17.71 \\
5 & No & -0.04 & 0.65 & 1.49 & -2.15 & 0 & -1.28 & 0.234 & 11.56 \\
5 & Yes & -0.099 & 0.92 & 0.85 & -1.84 & -1.1 & -1.32 & 0.174 & 14.27 \\
20 & Yes & -0.053 & 0.79 & 1.74 & -2.54 & 0 & -1.33 & 0.259 & 12.51 \\
20 & Yes & -0.048 & 0.76 & 1.56 & -2.33 & -2.58 & -1.28 & 0.26 & 11.61 \\
36 & Yes & -0.049 & 0.74 & 2.13 & -2.89 & 0 & -1.33 & 0.3 & 11.81 \\
36 & Yes & -0.041 & 0.69 & 1.83 & -2.54 & -3.39 & -1.25 & 0.3 & 10.79 \\
\hline
\end{tabular}

The momentum balance of an ISW plume is determined by a delicate balance between the approximately equal forces due to buoyancy, rotation, turbulent diffusion, and drag, as was systematically demonstrated in Holland and Feltham (2006). Our new drag law, by incorporating the physical process of variable drag direction depending upon plume depth, is more realistic than previous drag-law formulations. Further, we have shown that our drag law has a significant impact in determining ISW plume dynamics. The effect of our new drag law on the redistribution of mass beneath an ice shelf is difficult to predict without including frazil in the plume but, since the plume path is altered with the new drag law, one might expect modified regions of frazil ice deposition. Unfortunately, shortcomings in the ice shelf draft and marine ice thickness datasets at the high resolutions used in this plume modeling make it currently difficult to assess the likely impact of our new drag law on regions of frazil ice deposition (Holland and Feltham 2006).

Although we have focused on ISW plumes, the new drag law could easily be incorporated into other models that treat depth-averaged fluid layers adjacent to solid boundaries, such as plume models and isopycnic ocean models. In addition, the discretization spacing of most $3 \mathrm{D}$ ocean circulation models is such that the drag is related to the velocity averaged over some distance from the boundary. Our new drag law can be applied to any fluid-solid boundary, such as land/ice-air boundaries, sea ice-ocean boundaries, and bottom boundary currents in the ocean; however, the significance of the new drag law would need to be assessed for each of these cases since the dominant terms in the momentum balance will vary.

\section{APPENDIX A}

\section{Matching the Ekman Layer Solution to the Turbulent Boundary Layer Solution}

The constants $u_{0}$ and $v_{0}$ in the Ekman layer solution (2) are determined by matching the Ekman layer solu- tion to the solution in the turbulent boundary layer. We focus on the solution in the turbulent boundary layer by introducing the vertical coordinate $\zeta=\xi / \delta_{t}$, where $\delta_{t}=$ $\delta_{T} / \delta_{E} \ll 1$, and denote the solution with overbars. In the turbulent boundary layer coordinates the problem (1) takes the form

$$
\mathbf{O}\left(\delta_{t}^{2}\right)=\frac{d}{d \zeta}\left(a_{v} \frac{d \overline{\mathbf{u}}}{d \zeta}\right)
$$

with solution

$$
\overline{\mathbf{u}}(\zeta)=\overline{\mathbf{u}}\left(\zeta_{0}\right)+\frac{\delta_{T}}{\rho A_{m}} \boldsymbol{\tau} \int_{\zeta 0}^{\zeta} \frac{d \zeta}{a_{v}},
$$

where $\zeta_{0}$ is of arbitrary value and, to $O\left(\delta_{t}^{2}\right)$, the constant Reynolds shear stress in the turbulent boundary layer is $\tau=\left(\rho A_{m} a_{v} / \delta_{T}\right) d \overline{\mathbf{u}} / d \zeta$. As we are trying to determine the bottom condition in the Ekman layer, the particular form of $a_{v}$ is not important.

To match the Ekman and turbulent layer solutions, we first consider the latter as $\zeta \rightarrow \infty$,

$$
\begin{aligned}
\overline{\mathbf{u}}(\zeta \rightarrow \infty)= & \overline{\mathbf{u}}\left(\zeta_{0}\right)+\frac{\delta_{T}}{\rho A_{m}} \boldsymbol{\tau} \lim _{\zeta \rightarrow \infty} \int_{\zeta_{0}}^{\zeta} \frac{1+a_{v}-a_{v}}{a_{v}} d \zeta \\
& \sim \overline{\mathbf{u}}\left(\zeta_{0}\right)+\frac{\delta_{T}}{\rho A_{m}}\left(\zeta-\zeta_{0}+\int_{\zeta_{0}}^{\infty} \frac{1-a_{v}}{a_{v}} d \zeta\right) \tau
\end{aligned}
$$

As $\xi \rightarrow 0$, the Ekman layer solution (2) gives

$$
\tilde{\mathbf{u}} \sim U\left[u_{0}+\xi\left(s_{f} \boldsymbol{v}_{0}-u_{0}\right), v_{0}-\xi\left(s_{f} u_{0}+\boldsymbol{v}_{0}\right)\right] .
$$

Matching (A1) and (A2) requires

$$
\overline{\mathbf{u}}\left(\zeta_{0}\right)=\tilde{\mathbf{u}}(0)+\frac{\delta_{T}}{\rho A_{m}}\left(\zeta_{0}-\int_{\zeta_{0}}^{\infty} \frac{1-a_{v}}{a_{v}} d \zeta\right) \tau
$$

and

$$
\left.\frac{d}{d \xi}[\tilde{u}, \tilde{v}]\right|_{\xi=0}=U\left[s_{f} v_{0}-u_{0}, \quad-\left(s_{f} u_{0}+v_{0}\right)\right]=\frac{\delta_{E}}{\rho A_{m}} \tau .
$$



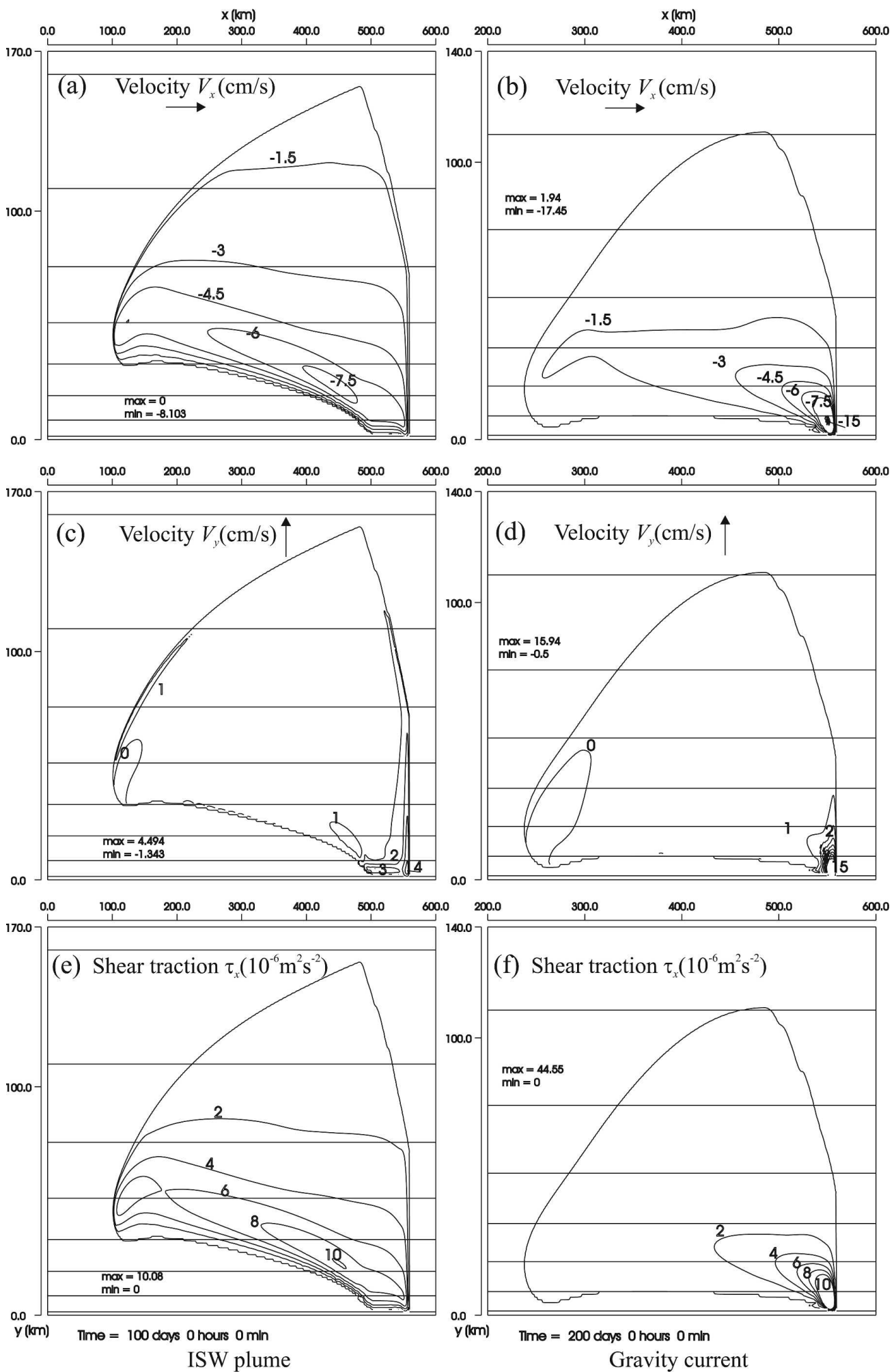

FIG. 9. The velocity and $x$ component of shear basal drag distribution for the (left) ISW plume and (right) gravity current at 100 and 200 days, respectively, for the proposed drag with $C_{q}=0.005$. 
The matching condition (A4) for the Ekman layer solution can be rewritten as

$$
\left.\rho A_{m} \frac{d \tilde{\mathbf{u}}}{d z}\right|_{z=0}=\frac{\rho A_{m} U}{\delta_{E}}\left[s_{f} v_{0}-u_{0},-\left(s_{f} u_{0}+v_{0}\right)\right]=\boldsymbol{\tau}
$$

[Eq. (3) in the main text]. The bottom condition for the Ekman layer solution requires that the shear stress determined by this solution is equal to the constant shear stress in the turbulent boundary layer.

As the fluid flow in the turbulent boundary layer is complex, in order to determine the bottom shear an experimentally validated drag law should be used. If, however, the precise form of $a_{v}$ is known and integrable at $\zeta=0$, then we can set $\zeta_{0}=0$ and the no-slip condition at the bottom (A3) will determine the bottom drag law

$$
\tau=\frac{\rho A_{m} U}{\delta_{T}}\left(\int_{0}^{\infty} \frac{1-a_{v}}{a_{v}} d \zeta\right)^{-1}\left[u_{0}+1, v_{0}\right]
$$

which, together with (A4), will constitute a closed set of equations for the normalized Ekman bottom velocities $u_{0}$ and $v_{0}$.

\section{APPENDIX B}

\section{Special Case of a Linear Drag Law}

In the special case of a linear turbulent boundary layer drag law given by (4) with $r$ constant, our new drag law takes a particularly simple form. In this case,

$$
\begin{aligned}
u_{0} & =\frac{-\chi(1+\chi)}{(1+\chi)^{2}+1}, \quad v_{0}=\frac{s_{f} \chi}{(1+\chi)^{2}+1}, \\
\mathbf{M}_{E} & =-\frac{U \delta_{E} \chi}{2\left[(1+\chi)^{2}+1\right]}\left[\chi, s_{f}(2+\chi)\right],
\end{aligned}
$$

and

$$
\boldsymbol{\tau}=\frac{\rho r U}{(1+\chi)^{2}+1}\left[2+\chi, s_{f} \chi\right],
$$

where $\chi=\delta_{E} r / A_{m}$. We estimate $\chi$ as being $\delta_{E} C_{q} b / A_{m}$, with $C_{q}=3 \times 10^{-3}$ and $A_{m}=5 \times 10^{-4} \mathrm{~m}^{2} \mathrm{~s}^{-1}$ (section $3 b)$. We estimate a typical mean plume speed to be 0.03 $\mathrm{m} \mathrm{s}^{-1}$ and set the bottom speed in the Ekman layer to be of this magnitude, that is, $b=0.03 \mathrm{~m} \mathrm{~s}^{-1}$. With these estimates, $\chi=0.57$ so that from (B1) the bottom speed is of the same magnitude as the mean plume speed, and our estimates are consistent. With $\chi=0.57$ we use (B3) to estimate the angle between the shear traction direction and the geostrophic velocity as about $-10^{\circ}$.

\section{REFERENCES}

Brown, R. A., 1974: Matching classical boundary-layer solutions toward a geostrophic drag coefficient relation. Bound.-Layer Meteor., 7, 489-500.

Döös, K., J. Nycander, and P. Sigray, 2004: Slope-dependent friction in a barotropic model. J. Geophys. Res., 109, C01008, doi:10.1029/2002JC001517.

Ezer, T., and G. L. Weatherly, 1990: A numerical study of the interaction between a deep cold jet and the bottom boundary layer of the ocean. J. Phys. Oceanogr., 20, 801-816.

Foldvik, A., and Coauthors, 2004: Ice shelf water overflow and bottom water formation in the southern Weddell Sea. J. Geophys. Res., 109, C02015, doi:10.1029/2003JC002008.

Gade, H. G., 1979: Melting of ice in sea water: A primitive model with application to the Antarctic ice shelf and icebergs. $J$. Phys. Oceanogr., 9, 189-198.

Holland, D. M., and A. Jenkins, 1999: Modeling thermodynamic ice-ocean interactions at the base of an ice shelf. J. Phys. Oceanogr., 29, 1787-1800.

Holland, P. R., and D. L. Feltham, 2006: The effects of rotation and ice shelf topography on frazil-laden ice shelf water plumes. J. Phys. Oceanogr., 36, 2312-2327.

Jenkins, A., and A. Bombosch, 1995: Modelling the effect of frazil ice crystals on the dynamics and thermodynamics of ice shelf water plumes. J. Geophys. Res., 100, 6967-6981.

Jungclaus, J. H., and J. O. Backhaus, 1994: Application of a transient reduced gravity plume model to the Denmark Strait outflow. J. Geophys. Res., 99, 12 375-12 396.

MacAyeal, D. R., 1984: Numerical simulations of the Ross Sea tides. J. Geophys. Res., 89, 607-615.

_ charge fluctuations: I. Unconfined ice tongues. J. Glaciol., 34, 121-127.

Makinson, K., 2002: Modeling tidal current profiles and vertical mixing beneath Filchner-Ronne Ice Shelf, Antarctica. $J$. Phys. Oceanogr., 32, 202-215.

Morland, L. W., 1987: Unconfined ice-shelf flow. Dynamics of the West Antarctic Ice Sheet: Proceedings of a Workshop held in Utrecht, May 6-8, 1987, C. J. van der Veen and J. Oerlemans, Eds., D. Reidel, 99-116.

Nicholls, K. W., and Coauthors, 2006: Measurements beneath an Antarctic ice shelf using an autonomous underwater vehicle. Geophys. Res. Lett., 33, L08612, doi:10.1029/2006GL025998.

Pedlosky, J., 1979: Friction and viscous flow. Geophysical Fluid Dynamics, Springer-Verlag, 174-183.

Rivaro, P., R. Frache, A. Bergamasco, and R. Hohmann, 2003: Dissolved oxygen, NO and PO as tracers for Ross Sea ice shelf water overflow. Antarct. Sci., 15, 399-404.

Sandhäger, H., D. G. Vaughan, and A. Lambrecht, 2004: Meteoric, marine and total ice thickness maps of Filchner-RonneSchelfeis, Antarctica. FRISP Rep. 15, 23-30.

Taylor, G. I., 1915: The eddy motion in the atmosphere. Philos. Trans. Roy. Soc. London, A215, 1-26. 